\title{
BLENDED LEARNING IN RESEARCH ORIENTED EDUCATION: TANGLE, AN EDUCATIVE SUITE FOR QUANTUM INFORMATION
}

\author{
Francisco Javier Delgado-Cepeda \\ Tecnologico de Monterrey, campus Estado de Mexico, Carretera a Lago de Guadalupe km. 3.5, \\ Atizapán, Estado de Mexico, Mexico. CP. 52926
}

\begin{abstract}
Quantum information is an emerging area of research which is growing rapidly and which is expecting to have a deep impact in the speed of information processing, storage and security. With only few decades of development, that trend has been highlighted as a remarkable economic focus for the development. Despite, this research area is barely identified in the general society as a source of opportunities for the personal development. The academic development for the most universities reacts slowly to these changes. Their educative programs are normally static with only some late adaptations to the newest technology or knowledge advancement, incorporating them in a limited strength. This research area, normally thought by the common people as proper for physicists, it is really open for lots of disciplines in nowadays. Any area with complex problems unable to be attained by classical computing could technically to be involved in this research trend. Thus, alternative new professional areas are emerging without be sufficiently visible for the universities in order to move the most traditional areas of education. Thus, in the next years, some emergent areas could be eclipsed in terms of human resources. In this arena, blended learning could contribute to provide novel educative contents as an alternative or complementary education to the main professional area selected. While, the blended learning approach is being developed to reach the most sectors of population with professional and university education. Strategies of blended learning are considered remarkable either for formal education as well specialized education to disseminate new trends not included in the traditional syllabus but important for the professional development of students. Because that is the case for Quantum information and Quantum computation areas having an explosive development just in the last decade, this work describes the outcomes around a blended learning initiative in the form of an educative suite for those areas with a multidisciplinary approach containing courses oriented to arrive into the formal research. Still, they are departing from the scientific divulgation until research collaboration going on through the formal learning. Suite was conceptualized with a multilevel approach to attract and to involve students from high school until graduate level.
\end{abstract}

\section{KEYWORDS}

Blended, MOOR, Physics, Mathematics, Research, Quantum information 


\section{INTRODUCTION}

In the current world, the knowledge society is a concept referring to a new focus in the development of countries. They normally imply the scientific development involving sciences and innovation together. Scientific content normally is associated with 20th century discoveries of advanced theories but with a limited technological scope. Nevertheless, in the beginning of the 21 st century, they have rapidly evolved in emerging technologies. The most of the technological world in nowadays is inherited in the form of traditional concepts and mathematics college curricula from the traditional science. New scientific knowledge normally requires a mathematical and scientific substrate often not included in the traditional engineering education. In addition, the promotion of such new educative areas closer than science should be planned since the youngest group being educated as a STEM initiative.

Last is the case for Quantum information, despite mainly a physics discipline, its extended research is evolving and spreading into several disciplines, generating accelerated growth in applications (as molecular biology, organic chemistry, logistics, big data processing, etc.) and advanced technology (as Cryptography, Quantum computation, Quantum internet, Quantum sensors, etc.). Properly, by its nature and complexity, it involves multidisciplinary approaches in its technological development: physics, mathematics, computer science, automation, as well as electronic and materials engineering. Thus, the development of specific competencies in each possible associated area should be considered to understand the inclusion in this research area through inclusively from classical disciplines but with problems expecting be able to being solved by quantum information processing.

The implementation of quantum computing systems is perhaps the most visible and ambitious goal of Quantum information. With particular areas of specialization and collaboration, it should be a focus of attraction for students of physics, electronic technologies, computer science and mechanical engineering. Particularly, in Latin America, the lack of organized and supported research and education in this area sets a gap between the attraction and the training of students. Learning resources have not been diversified and placed in simple terms for associated disciplines. Books and notes are rarely written in Spanish, the native language of students, in particular those related with scientific divulgation.

This work is related with an educative enterprise developed by a research group in Quantum information to raise the attraction towards this discipline in Latin American students. In the second section, we present the research and educative contexts on which the initiative is built. Third section presents the depiction of the development: Tangle, an educative suite of four courses involving tracks of inclusion departing from several levels and depths. That section presents also how Tangle has been developed and the educative activities in the research group originating its development. Fourth section presents a design for an introductory assessment for Tangle as a blended resource in a concrete educative activity. Fifth section present several outcomes related with the performance of Tangle in the context of the blended learning under the introductory assessment and in its current development. Conclusions are presented in the last section in terms the current achievements and opportunities. This work is an extended report of outcomes included in shorter versions around of Tangle's construction and operativeness in order to boost quantum information education by increasing the human resources in this research area in Latin America. 


\section{TANGLE: THE SUITE IN THE BLENDED LEARNING CONTEXT}

The areas of Quantum information and computation arise in the eighties and nineties originally from knowledge fields exclusive for physicists and mathematicians. Then, they began to flourish in terms of tangible developments accelerating the generation of applied knowledge. Today, there are clear evidences for their importance: two Nobel prizes (2012 and 2016), the creation of the first systems to establish quantum computation, the feasibility of establishing quantum information processing systems in terms of technology, and the growing world demand for human resources in science and engineering to develop them. In addition, there are statements of the National Science Foundation (NSF, 1999) and the European Economic Community (nIU, 2016) on the development of these disciplines as a priority. Thus, an accelerated development plan for the next 20 years has been addressed. But Mexico and the most of Latin American countries does not appear in the experts countries directory for the research area (UNIVIE, 2017), generating an opportunity to support investment on such initiative.

\subsection{Knowledge, Education and Society}

In the current age, world globalization and particularly of education is requiring an increasing number of students in disciplines such as science and technology. The same is true for research and development areas where the acquisition and mastery of knowledge is matched with high and specialized competencies.

Today, Quantum computation and Quantum information are emerging disciplines generating applications which will be soon part of everyday life in communications, computation, and information security. Thus, Quantum information, due to its complexity and diversification is suitable as a professional choice in the next years. Nevertheless, it becomes elusive in terms of training, mainly because students must be close with experts directing such training. There, the specialists should not know necessarily all the fundamental scientific and mathematical background formalism. In this sense, adequate education resources are not yet properly developed and diversified to tentative associated people into the research area. In addition, the field is not easily identified today by engineering or science students as a promising development area for them.

\subsection{Quantum Information inside STEM Education}

Disciplines around Quantum information are professional activities do not existing yet properly, neither wider recognized research areas or as stablished work activities. They are emerging as research and development activities where lots of professionals are opening new roads and widening highly valued professional assets in the immediate future. Thus, adequate educational resources are necessary to conduct students into them as a professional life possibility. The project being presented in this work is aligned with Science, Technology, Engineering, and Mathematics (STEM) initiatives. Quantum information comprises the highlighted goals of the United States National Research Council, the National Science 
Foundation (NSF, 1999) and the European Commission (nIU, 2016; UE, 2016), as a fundamental and priority area for technologically advanced societies.

Quantum information areas are exciting professional activities being developed in the current time. The youngest people could be the more enthusiastic about the opportunities being opened by this discipline in multiple fronts. The research area is becoming sufficiently wide to embrace several groups of professionals in disciplines as chemistry, biology, logistics, bioengineering, mathematics, physics, computer science, etc.

Quantum information processing group (QIPG) is a young research group working in those disciplines in Mexico with over 40 scientific publications in this area, more than 300 cites for the group research work, several research projects sponsored by CONACYT (the Mexican scientific research council), and collaborations with researches of United States, Italy, Canada and China (Figure 1). Despite, with only one postdoc, three doctors, two masters and seven undergraduate students, the group has a genuine interest in the human resources education in the discipline as a promising area of research and development. QIPG is a career ladder for master and doctoral students to engage them in international research projects. Still, the participation of some high school and undergraduate students in the group is oriented to learn and to develop basic associated research concluding in a scientific publication. Historically, three high school students (an educative level affiliated to our institution), seven undergraduate students (Physics, Computer Science and Engineering), 34 students in the formal optative course of quantum information processing and five graduate students in the research modality have been under the direction of the research group.

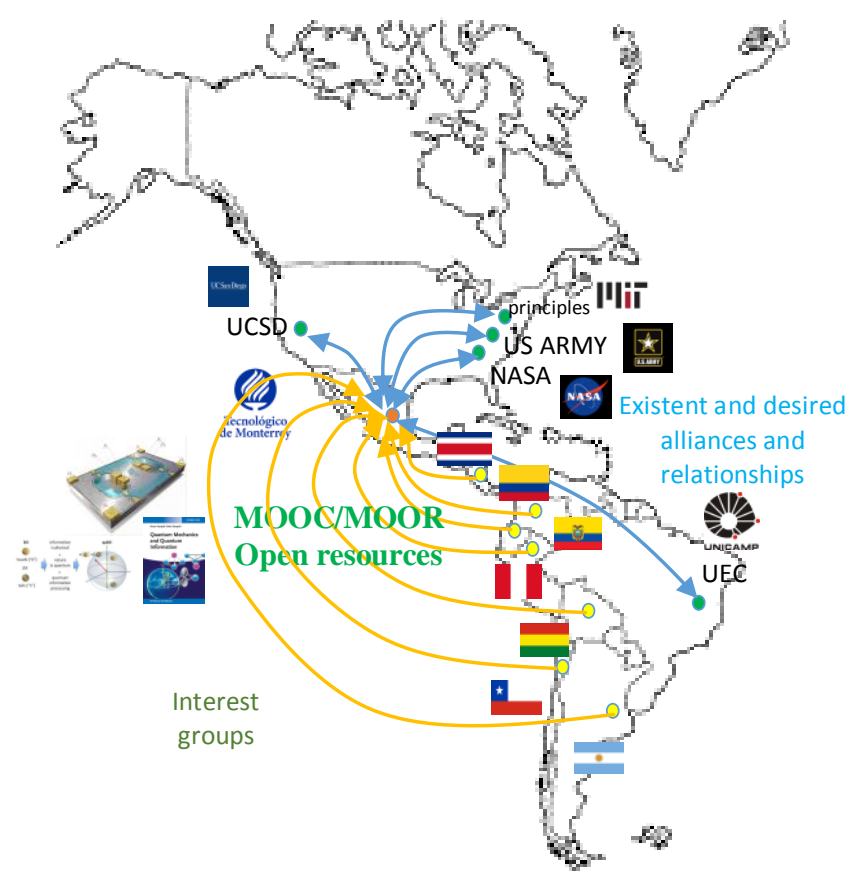

Figure 1. Ongoing and formally desired impact position and immediate relations of the QIPG 
IADIS International Journal on WWW/Internet

A current concern in QIPG is the lack of representation in Latin America of quantum information research, not displaying it as a high professional development area. Together, the absence of learning and training resources stratified by educative level does not address the interest departing from the early stages. In addition, the associated scientific literature is published in English generating a vacuum of early attraction for potential Latin America students. Still worst, in Mexico and Latin America there are a skill deficit in mathematics, physics and computing education which should be surpassed with complementary resources and attractive interest initiatives to reach the young people in order to engage them in those scientific activities. This perspective boosts the QIPG motivation to develop training resources hosted on an educative suite (called Tangle), particularly for Latin America students (Wade, 2014).

\subsection{Tangle: a Blended Learning Suite Combining Education and Scientific Collaboration}

Massive Online Open Courses (MOOC's) (Black, 2014) and Mobile Online Open Researches (MOOR's) (Hosler, 2014) are contemporary educative trends based on blended learning (Gleeson, 2014). They combine adequate resources and interaction to develop concrete learning or research (Weisskopf, 2015): tutorials, adaptive materials, screencasts, computer codes repositories, learning activities, discussion blogs, online classes, research projects, etc. Despite MOOC's sometimes are criticized by its student retention, MOOR's have an intrinsic motivation, either in his massive version (Hosler, 2014) or in the small group version (Goral, 2014; Delgado, 2017). MOOR's provides an emotional motivation in terms of the own future personal development.

Members of QIPG have developed certain experience in the implementation of MOOC's, MOOR's, Small Private Online Research (SPOR) and flexible evaluation based on blended learning with emphasis on research (Delgado, 2016a; 2016b) in other educational approaches. In addition, as the core interest, through Quantum information and Quantum computation summer schools organized in the past, students from Latin America countries (Colombia, Bolivia, Peru and Ecuador) have had punctual or extended approaches with QIPG, making plausible the attraction into the own local programs. The contribution in progress depicted in this paper is a long effort to set a group of courses including materials, applications and collaboration spaces under MOOC, SPOR and MOOR modalities integrated in an educational suite with a multi-level training format approach (covering High School, Undergraduate and Graduate as attraction focus).

For the students enrolled in the institution, the suite is being used through several courses normally included in the curricula of each level (Table 1). For the external students (national or international students), the suite becomes an open resource, but clearly it is seeking to attract them into the official programs of our institution related with QIPG (some of them inclusively in open summer research stays and prospective collaboration). In the next sections we depict the blended learning approach in the suite in order to contribute to the last goal. Then, some technical results are stated for an introductory assessment around the suite with an initial controlled group of students. It uses Tangle to support its ongoing design and the value of blended learning approach in it on a quantitative basis. 


\section{TANGLE DESIGN}

As a consequence of the experience integrating people into research, normally they coming from summer schools organized by QIPG or topic courses given to individual or reduced groups of students, together with some seminars with students sustained during some semesters, Tangle initiative collects some of that structure useful to conduct into the area to such students. The main goal was the full construction for a series of courses and resources grouped in the educative suite for the areas of Quantum computation and Quantum information. Being transversal for the three levels of Education, and moving through the scientific divulgation, the formal education until finally the research collaboration by settling there some research problems being attained to QIPG. Those courses and resources are differentiated and they are configurable to reach the several purposes: a) the attraction of students at all levels being considered with specific and directed activities for each of them, b) the basic and intermediate acquisition of skills necessary to be introduced to the Quantum information area, and c) the settlement of collaboration networks on concrete research problems (a potential laboratory for learning and research). This section barely states the Tangle's design together followed by an initial deployment and its outcomes in the SPOR format by using the first Tangle's module.

Table 1. Associated courses to introduce and/or to include Tangle resources (Delgado, 2018a)

\begin{tabular}{|c|c|c|c|}
\hline Associated courses & Level & Semester & Program(s) \\
\hline Experimental sciences IV & High school & $6^{\circ}$ & International Baccalaureate \\
\hline Quantum Information Processing & Undergraduate & $7^{\circ}$ & $\begin{array}{l}\text { Computer Sciences and } \\
\text { Physical Engineering }\end{array}$ \\
\hline $\begin{array}{l}\text { Topics of modality in scientific } \\
\text { research }\end{array}$ & Undergraduate & $7^{\circ}$ and $8^{\circ}$ & $\begin{array}{l}\text { Electronic, Mechanic and } \\
\text { Mechatronics engineering }\end{array}$ \\
\hline $\begin{array}{l}\text { Introduction to Quantum } \\
\text { Computation }\end{array}$ & Graduate & $2^{\circ}$ & $\begin{array}{l}\text { Nanotechnology graduate } \\
\text { programs }\end{array}$ \\
\hline Introduction to Spintronic & Graduate & $3^{\circ}$ & $\begin{array}{l}\text { Nanotechnology graduate } \\
\text { programs }\end{array}$ \\
\hline
\end{tabular}

\subsection{Tangle: Future Planned Overall Design}

The awakening of Tangle becomes as a series of resources, own and recommended to several groups of students being in contact with members of QIPG between 2008 and 2017. These materials were used and refined to attend, to include and to integrate those students. Some of them, the most in undergraduate engineering programs, shift their area on physics programs during their postgraduate studies. Other students continued or began postgraduate studies in computer sciences with a quantum computation orientation.

Tangle's contents are mainly based on a series of learning modules as MOOC's and MOOR's approaches. The introductory topics are more oriented into the acquisition of basic and intermediate tools for Quantum information and Quantum computation. Modules are reconfigurable for several alternative depth levels and profiles: scientific, engineering and computational, together with introductory divulgation issues for all levels, but mainly for High School students. Different methodologies used in each module is according to the audience, the context and the contents. Normally, several approaches of Connectivism (Siemens, 2005) are used: active learning, blended learning, and learning based on research. Figure 2 (Delgado, 
IADIS International Journal on WWW/Internet

2018a) depicts the general structure and planning (for some sections still being developed) for the suite. At this stage, only the first two modules are active.

There are an incipient or null historical record in the academic impact of quantum information education as emerging area because it normally transcends the classical curricula. Worse, there is an empty register for the general novel education in research areas. The first attempts are pursued as a consequence of STEM initiatives, thus, only by departing from these experiences, in some years we could to know the outcomes on the scientific research due to the STEM effort. In terms of the roadmap presented in (Delgado, 2018a), the future research objectives around of Tangle should include: a) rising of user's demographic statistics (AAa), b) learning analytics assessment for the level of contents coverage (AAb), performance (AAd) and captivation (AAc) of participants through the suite's courses and levels, an aspect highlighted in the literature around of this kind of resources. The relations between the didactical elements in Tangle and planned analytics are depicted in the Figure 3.

\section{Group research}

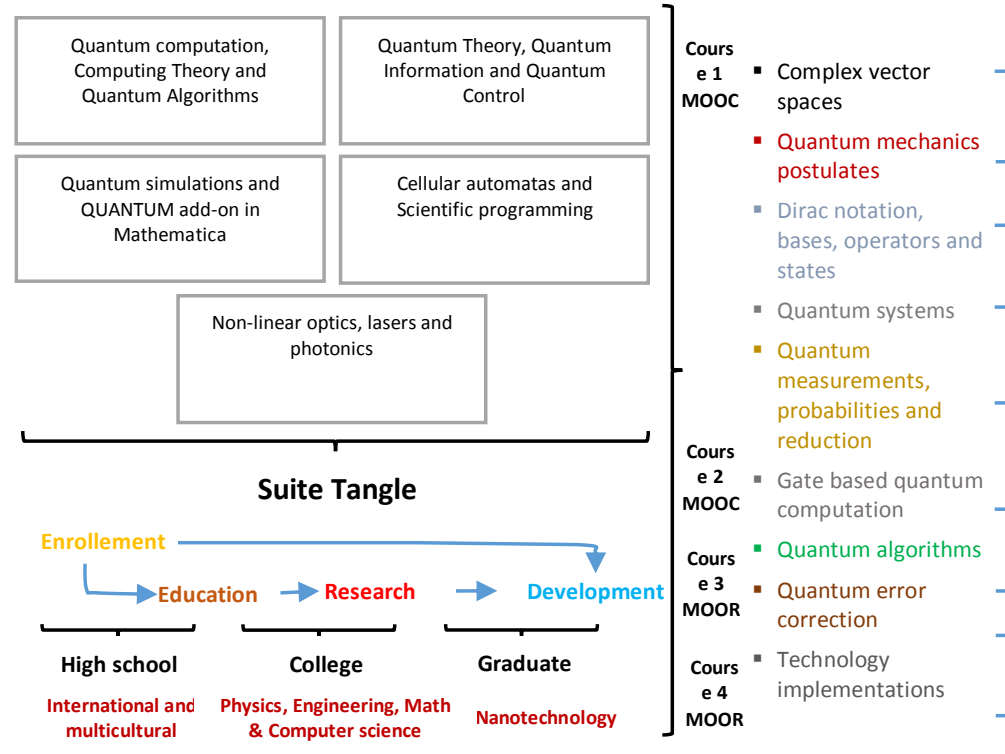

MOOC/MOOR contents

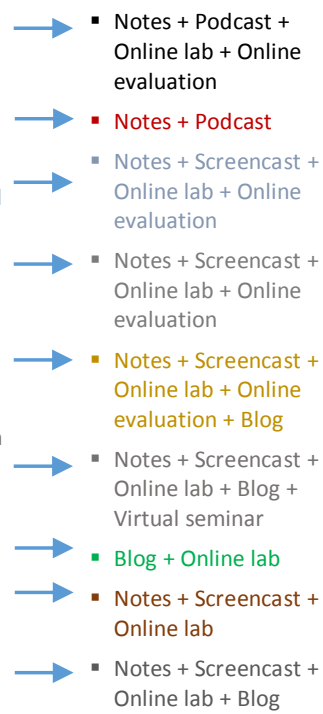

Figure 2. QIPG expertise, plan courses, and resources under a multilevel scope (Delgado, 2018a)

\subsection{Previous Experiences using TANGLE while it was being developed}

As was stated before, Tangle's birth arises in a couple of quantum computation summer schools organized by QIPG in 2008 and 2010. Then, a series of conferences given by QIPG members to introduce the audience into the area, the most undergraduate students, were accompanied by several specialized talks from invited speakers. Such experiences open to QIPG into the Quantum information arena in terms of student identification, thus, students 
from Equator, Colombia, Paraguay and Mexico of course, kept in touch with the group. Some of us were invited to those countries to share the QIPG research.

Further educative activities were conducted. A first quantum information processing course for computer science and electronic engineering students was officially stated in 2014 in our institution, which is commonly open one time on the year. This course is a valid topic for Computer science students. Nevertheless, other students in other engineering programs commonly become related with QIPG through research stays for undergraduate students in engineering, a one year experience working with a researcher in the group, which in the last time ends with an original research work being published. In those experiences, normally some high school students join to the seminars. In addition, summers stays of research are open for all external students (high school to postgraduate levels) through the Mexican Research Council (CONACYT). There, students spend two months working with a researcher of QIPG.

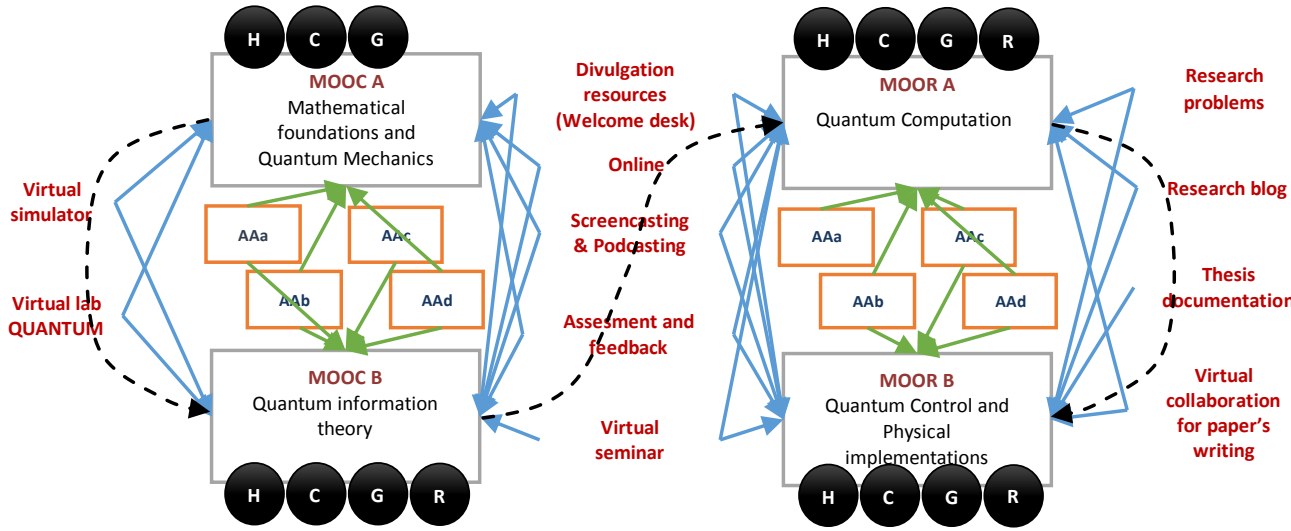

Figure 3. Learning elements for each course, target public (H: High School, C: Undergraduate, G: Graduate, R: Research) and associated immersed analytics (AAa, AAb, AAc, AAd) (Delgado, 2018a)

Some aspects of Tangle are shown in the Figure 4. Each course has a particular place in the suite. MOOC's follow a complete section by section design, including first the scientific divulgation materials in the form of videos and animations. Then, introductory reading is provided before the most formal content. Evaluation is included in the most of sections. Thus, student can access to all materials to begin from the easier parts of each section.

\section{AN INSIGHT ASSESSMENT FOR TANGLE}

\subsection{Structure of the Blended Workshop}

Despite previous approaches has been used in the previous educative activities of QIPG, for the initial design of Tangle (first module) in its current stage, the first activity offered was a two week workshop in Quantum information and Quantum computation. The pretension of workshop was to be offered as a nationwide activity inside of institution (we are spread in 31 campus in Mexico). It was finally implemented with 25 undergraduate students of Computer Science, Physics and Engineering who rolled out for an immersive experience of two weeks in 
IADIS International Journal on WWW/Internet

the form of a blended learning experience during the activity called "Semana I", the name in Spanish for the week of innovation and research (Delgado, 2018b). It is a yearly mandatory activity for the students at Tecnológico de Monterrey in order to attend a creative, social or research task organized in the institution. Tecnológico de Monterrey started three years ago with such practice, a yearly event where all undergraduate students develop one proposed challenging learning activity (related or not with their fields of study). Thus, during 2017, QIPG proposed there (for interested students in science and engineering) a workshop in quantum information being supported by the first version of Tangle's resources.

Because the official term is one week as a face-to-face activity, the previous week to the "Semana I" was conducted completely online using Tangle. The objective was to develop basic knowledge in this discipline to then propose tentative related future research culminating in a scientific publication of his authorship during a subsequent space (research modality or graduate studies). It was an approximation for the implementation of Tangle for the first module.

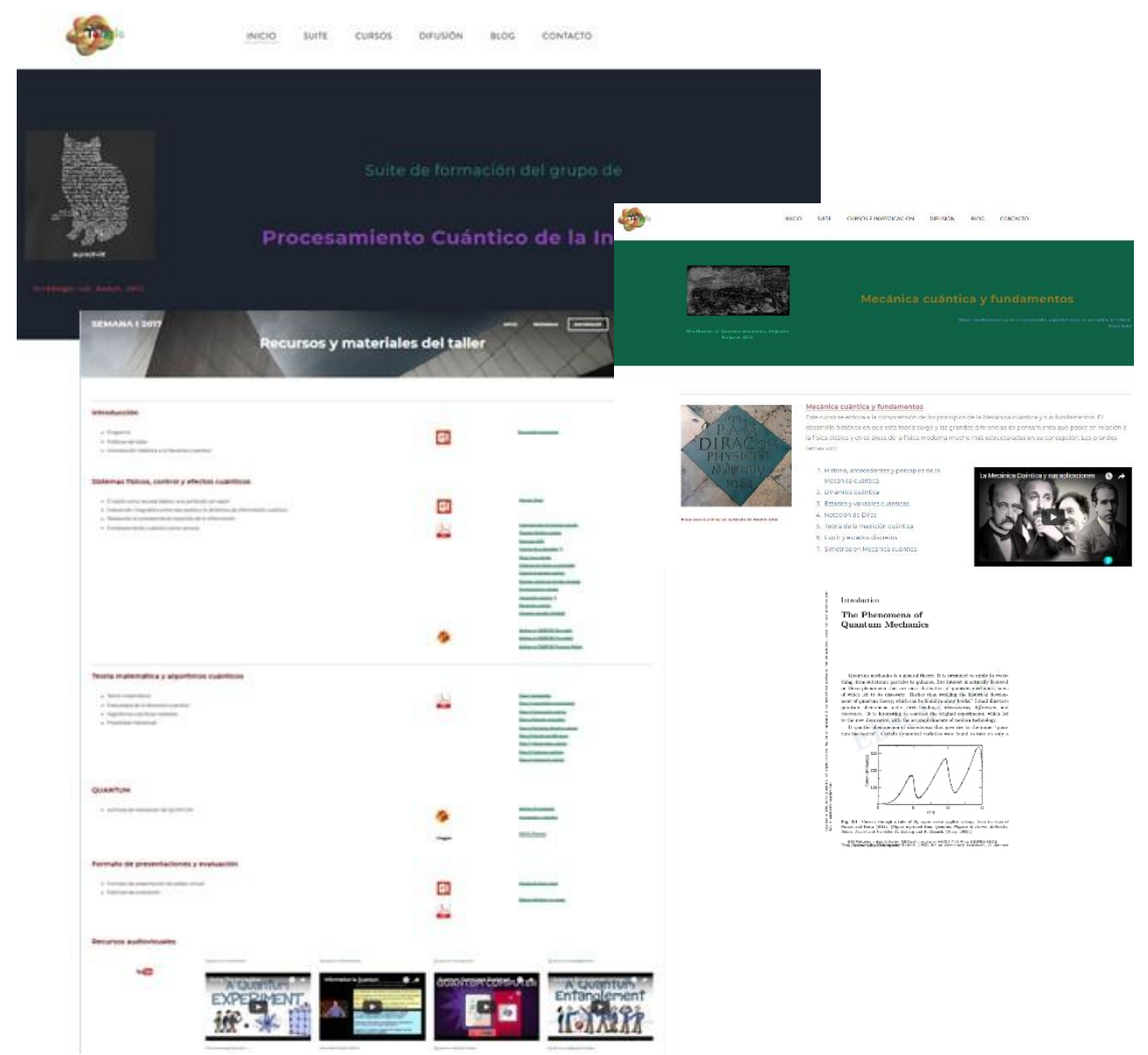

Figure 4. Several aspects in the Tangle's content. Each course is integrated containing divulgation materials (videos, animations), activities, book materials, notes, etc 


\subsection{Objectives for an Introductory Research}

The workshop was conducted during two weeks as was previously depicted. The workshop covered the students' interest on research, presenting issues related to emerging areas in this scientific research with a foresight of professional development. Activity was offered and developed in Mexico City as a nationwide activity (open to all students in the 31 campuses of Tecnológico de Monterrey and with a final enrolment of students from eight cities spread across all México: Monterrey, Guadalajara, Querétaro, Puebla, Pachuca, Chihuahua, San Luis Potosí and México City). It was based on a previous week of online preparation following a set of materials (lectures, practices, and podcasts). The first online week covered a series of materials contained in the first module of Tangle, from divulgation until elementary lectures introducing the concepts and the mathematics involved. Each student covered those materials and the related activities at his own pace during that week. Those contents effectively covered were tracked for each student, despite it was not an element of the formal evaluation for the "Semana I" activity, they let to set some correlated outcomes in the analysis. This informal following was called the "Online grade" for each student, and it assumed as requisite for the face-to-face section in the workshop.

Face-to-face component of the workshop was developed in México City. The students came from seven different cities of México, far away so much as one thousand kilometres. They were enrolled between semesters from $2^{\text {nd }}$ to $9^{\text {th }}$. Demography is reported in Table 2 as it was presented in (Delgado, 2018b). For this component, students attended some key lectures before the practice with algorithms, programming and research development. Several aspects were evaluated individually through an observation guide and specific rubrics in the overall activities): participation (effective work in terms of intervention and support to their team) together leadership (conducting some development in their teams). This component in the student's evaluation was labelled as the "Face-to-face grade". Finally, because the goal was to construct a research proposal, this was another evaluation component assigned for each team: the report quality and the innovation in the proposal (there, a discrete scale was defined: $100 \%$ for new problems, $75 \%$ for complex problems but commonly studied in the literature, and $50 \%$ for problems do not reaching some of these standards), together an individual performance in the public proposal presentation to differentiate the team note for each team member. This component was called the "Quality final product grade". Together, face-to-face grade and quality final product grade were combined into the "No-online grade" (the only grade officially reported for the overall activity).

Table 2. Students' demography in the quantum information workshop (Delgado, 2018b)

\begin{tabular}{|c|c|c|c|c|c|c|c|c|}
\hline \multirow{2}{*}{ GENDER } & \multicolumn{4}{|c|}{ Female } & \multicolumn{4}{|c|}{ Male } \\
\hline & \multicolumn{3}{|c|}{3} & & \multicolumn{4}{|c|}{22} \\
\hline \multirow{2}{*}{ PROGRAM } & \multicolumn{3}{|c|}{ Engineering } & \multicolumn{3}{|c|}{ Computer science } & \multicolumn{2}{|c|}{ Physics } \\
\hline & \multicolumn{3}{|c|}{10} & \multicolumn{3}{|c|}{11} & \multicolumn{2}{|c|}{4} \\
\hline \multirow{2}{*}{ SEMESTER } & $2^{\text {nd }}$ & $3^{\text {rd }}$ & $4^{\text {th }}$ & $5^{\text {th }}$ & $6^{\text {th }}$ & $7^{\text {th }}$ & $8^{\text {th }}$ & $9^{\text {th }}$ \\
\hline & 4 & 7 & 4 & 2 & 2 & 2 & 2 & 2 \\
\hline \multirow{2}{*}{ ORIGIN } & \multicolumn{4}{|c|}{ Local (México City) } & \multicolumn{4}{|c|}{ Non-local } \\
\hline & \multicolumn{4}{|c|}{14} & \multicolumn{4}{|c|}{11} \\
\hline
\end{tabular}


There are several interests in the current research. They are around of the effectiveness of online component on the overall activity and on the blended scheme. Some concerns in this experience were the assessment about as the online component of learning could conditioning the no-online one (particularly that related with the final product quality performance), together, we were interested on the students' perception. Thus, we set the following three objectives in this research work:

a) To measure de degree of correlation between the performance in the two components of workshop as causal facts: online performance versus face-to-face performance

b) To measure the degree of statistical influence from the online performance and the face-to-face performance on the final quality performance

c) To track which became the online learning coverage distribution on the student population and its relation with the no-online evaluation (the overall evaluation in the workshop)

d) To track the students' perception about the quality and organization of workshop

e) To set the correlation between some aspects of students' perception with the overall performance of workshop

The following section sets the main results related to the last objectives in order to assess the Tangle development in the experience depicted.

\section{OUTCOMES AND DISCUSSION}

\subsection{Comparing Online Performance and Face-To-Face Performance versus the Final Product Quality}

To attend the first two objectives, we develop several analysis. The outcomes are summarized in the Figure 5 and in the Table 3. 


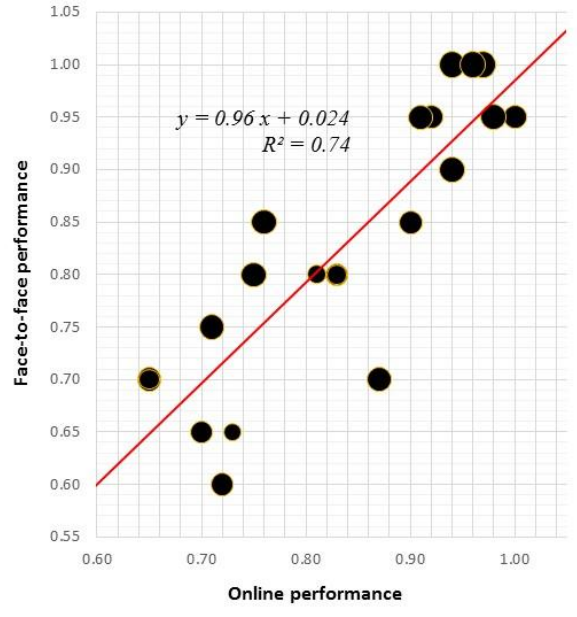

a)

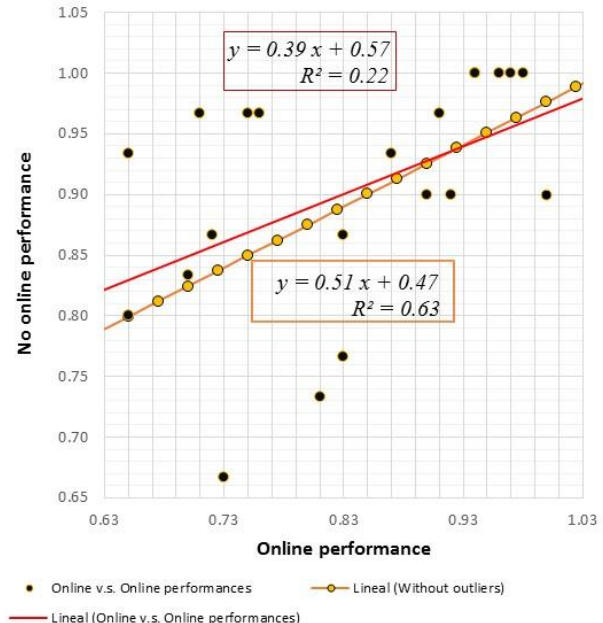

b)

Figure 5. Online and Face-to-face performance vs. Final product quality

By comparing each register for the effective individual coverage of materials tracked in the online component of the workshop together with the individual performance during the face-to-face workshop as was depicted in the last section, we get a linear correlation between both performances (Figure 5a) with an outstanding correlation coefficient $R=0.86$ as follows (Delgado, 2018a). The outcomes were reported in a 0-1 grade scale re-scaled from their original 0-100 grade scale for simplicity. The dispersion graph shows both performances for each student in black dots. There, the radius is proportional to the final product quality grade. As a conclusion, there are not conclusive evidence in the close relation between the usage of online materials in the previous week with the face-to-face component and the final quality product. It has been assumed that the social knowledge exchange in the teams during the workshop could explain such behaviour.

In other analysis (Delgado, 2018b), the overall grade assigned to each student in the workshop (the no-online grade) was similarly compared with the online performance. The dispersion plot is reported in the Figure 5b. There, two linear fits are shown. The red line represents the direct correlation exhibiting a low correlation coefficient $R=0.47$, while the yellow line excludes the outliers with a correlation coefficient of $R=0.79$.

For more conclusive outcomes between the differences established on the online, face-toface and quality final product performances by the online component, we run a couple of twofactor ANOVA tests $(p=0.05)$ comparing extreme behaviours by splitting the group of students in two subgroups: a) those having online performances larger than 0.7 , and b) those with lower than 0.7. Outcomes are reported in the first part of Table 3 (Delgado, 2018a) for the difference on the face-to-face performance in both subgroups, showing statistical evidence for the impact of online performance on the face-to-face performance between both subgroups $(p=0.0002<0.05)$. While, the second part of Table 3 shows the outcome for the difference in the final quality performance, not exhibiting statistical difference between two groups $(p=0.3060>0.05)$, as previously suggested the Figure 5a. 
IADIS International Journal on WWW/Internet

Table 3. ANOVA tests discriminating differences between online performance on other performances

ANOVA for Face-to-face performance based on Online performance difference

\begin{tabular}{lcccccc}
\hline \multicolumn{1}{c}{ Source } & S.S. & d.f. & M.S. & $F_{\text {calc }}$ & $p$-value & $F_{\text {critical }}$ \\
\hline Between & 0.167 & 1 & 0.167 & 19.705 & 0.0002 & 4.381 \\
Whitin & 0.161 & 23 & 0.008 & & & \\
Total & 0.328 & 24 & & & & \\
\hline
\end{tabular}

ANOVA for Quality final product performance based on Online performance difference

\begin{tabular}{lcccccc}
\hline \multicolumn{1}{c}{ Source } & S.S. & d.f. & M.S. & $F_{\text {calc }}$ & $p$-value & $F_{\text {critical }}$ \\
\hline Between & 0.010 & 1 & 0.010 & 1.106 & 0.3060 & 4.381 \\
Whitin & 0.176 & 23 & 0.009 & & & \\
Total & 0.186 & 24 & & & & \\
\hline
\end{tabular}

\subsection{Distribution of the Online Performance and Association with No-Online Performance in TANGLE}

The analysis of the third objective is developed as follows. By splitting the students in six classes in agreement with the online performance in the population, we get the Figure 6 exhibiting a two peaks distribution with extreme behaviours for the material coverage (Delgado, 2018a). Thus, while many students covered the most of online materials, other subgroup shows an initial low coverage. There, as comparison, the average for the overall no-online performance in each class is shown (red line), revealing barely how a poor coverage seems to determine the face-to-face and goal performances in the workshop despite the team scaffolding. A brief of the all previous outcomes, there are certain evidence about the usefulness of the online materials to improve the knowledge and performance during the face-to-face component of workshop.

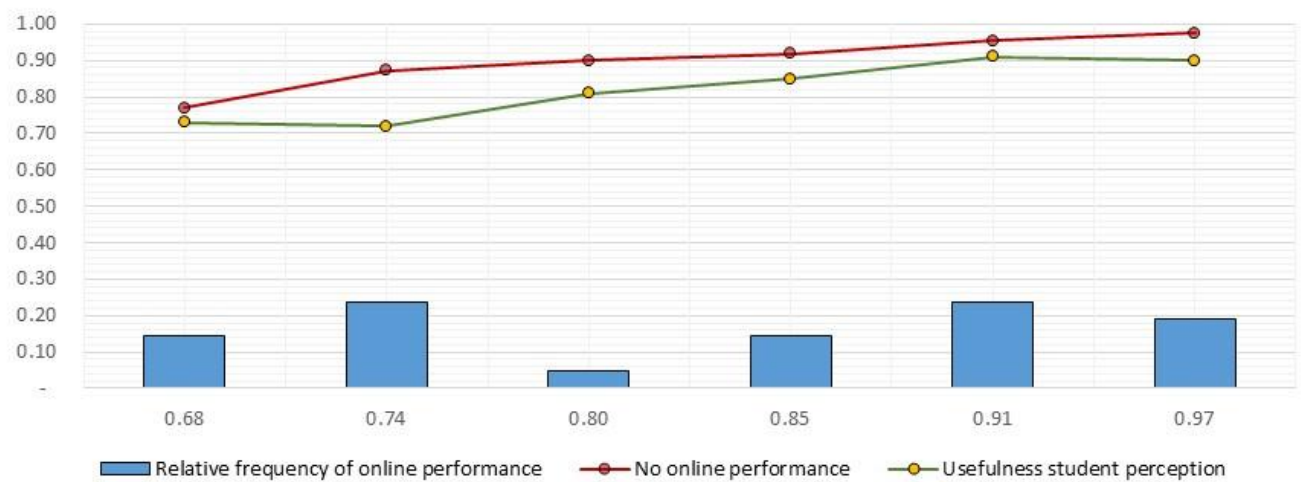

Figure 4. Relative frequency of online performance vs. No-online performance (Delgado, 2018a)

Despite the workshop was not completely similar to the correspondent course planned as a MOOC, mainly in terms of the pace (nevertheless note workshop had an effective intensive duration of 60 hours in comparison with the course using around of 80 hours). The materials used in Tangle to prepare the students were the same, covering the physical concepts and mathematics involved in the basic quantum information theory. Students should activate previous knowledge in vector spaces, complex numbers and state diagrams to understand the basics of quantum information processing theory. The face-to-face interaction in the workshop 
lets to present other crucial aspects in quantum mechanics principles, quantum evolution, and other advanced topics, which despite they are included in the MOOC, they were presented during the second week as a blended approach.

As was noted in (Delgado, 2018a), there an outstanding aspect in terms of the statistical independence between the performance shown in the final presentation of the proposal for the research project and the online performance. This aspect possibly could be explained as a result of the learning achieved in the social interaction during the face-to-face component, supporting the belief about the valuable supremacy of the blended learning on the pure online approach.

\subsection{Perception of Students on the Workshop's Quality}

Several aspects during the workshop from the point of view of students were raised through a final survey. Scale used was $0-10$ where 10 is the best and 0 the worst. Aspects raised in the survey covered (Delgado, 2018b) a) Clear evaluation politics and Clear evaluation (transparency), b) Assessment during the workshop by the researchers, c) Inclusion of New concepts, d) Motivation to reinforce the own Attitude during the workshop, e) Methodology and Reflection spaces to promote the learning, f) Usefulness and the Social value given to the workshop, and g) Challenge level that the workshop had symbolized. We reproduce the outcomes presented in (Delgado, 2018b) in the Figure 5 (continuous black line). Outcomes are highly consistent (note the range evaluations in red dotted lines) and they show an outstanding evaluation in all aspects. In an additional institutional evaluation asking the question (on a Likert scale): "will you recommend to your partners this "Semana I" activity?" the outcome was 4.82 from 5 possible ( 5 is the best). Finally, because in the survey applied by QIPG students were identified, then we tracked and grouped the outcomes in terms of the section 5.2, they are shown in the Figure 4 as a green line and scaled by 10 . This new aspect not reported before could explain the two-peak distribution in that plot.

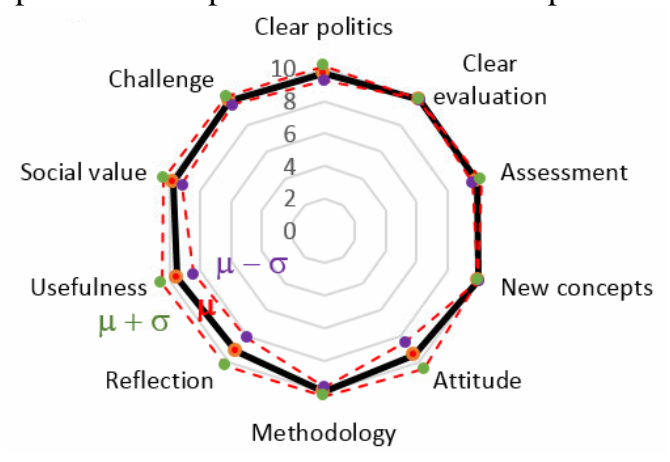

Figure 5. Average outcomes in the eight-dimensional students' perception survey for the workshop (Delgado, 2018b) 


\section{CONCLUSIONS}

The revolution imposed by Internet has been changing lots of unimaginable aspects in our lives. Sometimes imperceptibly and slowly, thus are some aspects of Education. In anyway, our society is changing deeply in a few decades the most of stablished since the last technological revolution in the $18^{\text {th }}$ century. The changes in the curricula necessities sometimes advance faster than the academic organization does. Contemporary schemes of instruction impose a different rate of effective development and flexibility because they are variable. Blended schemes are appearing in our society inside or out the university to propose alternative knowledge to that stablished formally in the professional programs. Those contents advance in an unorganized way at the time they are generated.

Several of those schemes will be available for new generations in the next years in an open way. Then, it is clear that new generations are learning in a different way. Novel courses not adapted to the traditional curricula (that supporting our present world), will be evolved into MOOC, MOOR or SPOR schemes, changing the higher education approach as it had been known. Such is for the experience depicted here, where despite Quantum information have currently certain structured basic knowledge, it is assumed as possible after of some education level, which is partially not true. Youngest people needs every day more engaging experiences for their inclusion in the market workplace. In those terms, transversal and multilevel Education (as here proposed) will be more common as in the old history of Education.

Skills and professional competencies require a continuous and growing practice through concrete steps to be owned. It simply supersedes any course extent. The requirement of the coverage and dominion of certain knowledge as requisite is highly structured and sometimes inefficient for the interests of young people, in particular because the contents in Education have been increasing continuously eclipsing some interesting novel areas of knowledge and applications which are engaging them. Last is particularly true for people interested in research. Those people are normally self-directed, but they are interesting sometimes in the top of the knowledge and applications, which is contradictory with the traditional educative scheme. Then, traditional and unfinished preparation promotes the extinction of such interest. A new approach should be developed for this young people compromised to give his effort in the research quest by introducing them into the research arena directly by using basic aspects to have a first understanding, which then engage them in a more compromised education to then deep their learnings. Evaluation is another issue to be adapted to these changes. Despite necessary, evaluation should to beyond the content knowledge, in the arena of skills and competencies development. Both aspects, learning and evaluation are complex tasks for teachers in the current world education (Schwartz, 2014), as well for researchers to prepare new generations to stand in for the research work. Such was the pretension for the challenge offered during the "Semana I" for the quantum information workshop and the guideline for the Tangle suite construction. There, Internet is working as a promotor not only from knowledge, instead of its proper dissemination in a new kind of society which is emerging every day with new ideas and resources, particularly in the Education arena. 


\section{REFERENCES}

Black, D., 2014. MOOCs and the Move Toward Competency-Based Education. Retrieved from: http://moocs.com/ index.php/moocs-and-the-move-toward-competency-based-education/

Delgado, F., 2016. Follow-up on a Numerical Methods Course Using m-learning and Proposal for an Evolution to Research Based Learning. Proceedings of The Eight International Conference on Mobile, Hybrid, and on-line Learning 2016.

Delgado, F., 2016. Upgrading to Numerical Methods Course into New Mobile Technologies for Mathematical Education: An Approach Based on Flexibility and Skill Development. In Mobile and Blended Learning Innovations for Improved Learning Outcomes (David Parsons, ed.). IGI Publishing: London.

Delgado, F., 2017. Small Private Online Research: A proposal for a Numerical Methods course based on Technology use and Blended Learning. Proceedings of Mobile Learning 2017.

Delgado, F., 2018. Tangle: a blended educative suite for the quantum information education and development of research skills. Proceedings of e-Society 2018.

Delgado, F., 2018. A learning challenge for a multidisciplinary quantum information and quantum processing workshop during "Semana I". Proceedings of INTED 2018.

Gleeson, T., 2014. Co-Teaching a Blended Class across Universities. Inside Higher Ed. Retrieved from: http://www.insidehighered.com/blogs/higher-ed-beta/co-teaching-blended -class-across-universities

Goral, T., 2014. SPOC's may provide what MOOC's can't. University business. Retrieved from: http://www. universitybusiness.com/article/spocs-may-provide-what-moocs-can\%E2\%80\%99t

Hosler, A., 2014. Massive Open Online Research: The MOOC Evolves into the MOOR. Retrieved from: http://www. emergingedtech.com/2014/01/massive-open-online-research-the-mooc-evolves-into-themoor/EmergingEdTech

nIU, 2016. Quantum Europe 2016: A New Era of Technology. European Commission. Retrieved from: http://gdriqfa. unice.fr/IMG/pdf/quantumeurope2016_report.pdf

NSF, 1999. Quantum Information Science: An Emerging Field of Interdisciplinary Research and Education in Science and Engineering. Retrieved from: https://www.nsf.gov/pubs/2000/ nsf00101/nsf00101.htm

Siemens, G., 2005. Connectivism: A Learning Theory for the Digital Age. International Journal of Instructional Technology and Distance Learning, vol. 2, no. 1, pp. 3-10.

UE, 2016. Quantum Manifesto: A new era of technology. European Union. Retrieved from: http://horizon2020.mon. bg/en?h=downloadFile\&fileId=86

UNIVIE, 2017. Research in Quantum Information Directory. Vienna University. Retrieved from: http://www.vcpc.univie.ac.at/ ian/hotlist/qc/research.shtml

Wade, G., 2014. New model needed to close widening education gap. Retrieved from: http://www.universityworldnews. com/article.php?story=20141121091229767

Weisskopf, V., 2015. CERN: A Model for International Research. CERN. 